\title{
DETECTION OF TOXIGENIC CLOSTRIDIUM DIFFICILE STRAINS ISOLATED FROM MEAT AND MEAT PRODUCTS IN IRAN
}

\author{
E. RAHIMI ${ }^{1} \&$ F. KHAKSAR ${ }^{2}$ \\ ${ }^{1}$ Department of Food Hygiene, ${ }^{2}$ Graduated Student of Food Science and \\ Technology; Faculty of Agriculture, Shahrekord Branch, \\ Islamic Azad University, Shahrekord, Iran
}

\section{Summary}

Rahimi, E. \& F. Khaksar, 2015. Detection of toxigenic Clostridium difficile strains isolated from meat and meat products in Iran. Bulg. J. Vet. Med., 18, No 3, 277-281.

The aim of this study was to determine the occurrence of toxigenic $C$. difficile in some of the meat products in Iran. Samples of hamburger (100), minced beef meat (150), chicken nugget (150), sausage (100) and canned meat (70) were collected from the retail trade and analysed for the presence of $C$. difficile using selective enrichment in $C$. difficile broth, subsequent alcohol shock-treatment and plating onto $C$. difficile selective medium. $C$. difficile isolates were tested for determination of toxins $\mathrm{A}$ and $\mathrm{B}$ production by enzyme linked immunosorbent assay. Of 570 samples tested, six $(1.2 \%)$ were positive for the presence of $C$. difficile: one from hamburger $(1.0 \%)$ and five from minced beef meat (3.3\%). Among six $C$. difficile isolates five $(83.3 \%)$ were found to be toxigenic and were positive for toxin A and/or B. This study shows the importance of minced beef meat as potential source of $C$. difficile infection in people who consume it.

Key words: Clostridium difficile, meat, meat products, toxigenic strains

Clostridium difficile is recognised as a nosocomial pathogen associated with antimicrobial drug-associated diarrhoea and pseudomembranous colitis in humans and the infection is believed to be acquired nosocomially. $C$. difficile has also been shown to be an important pathogen causing diarrhoea in humans in communities outside hospital environments (Chernak et al., 2005). Reports from Canada, USA and Europe indicate that a large proportion of these cases of community-acquired C. difficile infection (CA-CDI) are not linked to recent antibiotic therapy, older age, significant comorbidity or previous hospitalisation (Wilcox et al., 2008; Bauer et al., 2009). In addition, recent epidemiological data indicate that the incidence and severity of the disease appear to be increasing worldwide (MacCannel et al., 2006).

Toxigenic strains of $C$. difficile typically produce 2 major toxins, $\mathrm{A}$ and $\mathrm{B}$, although a small percentage produce only toxin B (Pituch et al., 2006). Certain strains may also produce a binary toxin 
(known as CDT), whose clinical relevance is under investigation. Ribotype 027 and 078 strains produce all 3 toxins. This strain has been implicated in recent outbreaks of severe disease internationally and is also a common endemic strain in many regions (Goorhuis et al., 2007; Hubert et al., 2007; Songer et al., 2009).

Food animals are an important source of human enteropathogenic microorganisms and can be spread to men through consumption of foods of animal origin. In accordance herewith, recent reports show a remarkable overlap between isolates from animals and humans (Goorhuis et al., 2008). In recent studies $C$. difficile has been isolated from several food animal species and variety of foodstuff, sharing high level of genetic similarity with those of human isolates (Simango, 2008; Rupnik et al., 2009; Weese, 2010).

The epidemiology of $C$. difficile infection (CDI) in Iran is essentially unknown. Although toxigenic $C$. difficile isolation has been reported from Iranian hospitals (Jalali et al., 2012), to the authors' knowledge, there is limited information regarding the prevalence rate of $C$. difficile in foodstuff in Iran (Esfandiar et al., 2014; Rahimi et al., 2014a,b). The present study was conducted to determine the prevalence of toxin producing $C$. difficile strains isolated from retail meat products in Isfahan, Iran.

From April to October 2012, a total of 570 meat product samples including hamburger $(n=100)$, minced beef meat $(n=150)$, chicken nugget $(n=150)$, sausage $(n=100)$ and canned meat $(n=70)$ were purchased from randomly selected retail stores in Isfahan and Shahrekord cities in the center of Iran. All samples were placed in separate sterile plastic bags to prevent spilling and cross contamination and were immediately transported to the laboratory in a cooler with ice packs and processed within $6 \mathrm{~h}$.

The detection and isolation method used was based on the method described by Rodriguez-Palacios et al. (2007) and de Boer et al. (2011). Briefly, $5 \mathrm{~g}$ of each sample was transferred to $20 \mathrm{~mL}$ of $C$. difficile broth (CDB), containing $C$. difficile selective supplement (Oxoid SR0173) and $5 \%(\mathrm{v} / \mathrm{v})$ defibrinated sheep blood. After inoculation at $37{ }^{\circ} \mathrm{C}$ for 10 to 15 days under anaerobic conditions, $2 \mathrm{~mL}$ of the enriched broth was added to $2 \mathrm{~mL}$ of $96 \%$ ethanol in a centrifuge tube and homogenised during $50 \mathrm{~min}$ on a shaker. After centrifugation $(3800 \times \mathrm{g}$ for $10 \mathrm{~min})$, a loopful material from the sediment was streaked onto $C$. difficile agar base (Oxoid CM0601) supplemented with an antibiotic supplement for the selective isolation of C. difficile (Oxoid SR0174) and 7\% (v/v) defibrinated sheep blood, and the plates were incubated for 24 to $48 \mathrm{~h}$ at $37{ }^{\circ} \mathrm{C}$, under anaerobic conditions. Up to three colonies per plate were subcultured onto tryptone soya agar (Oxoid CM0131) and tested by standard microbiological and biochemical procedure (Harvey et al., 2011). Crudely extracted DNA (boiling, $10 \mathrm{~min}$ ) was used for PCR confirmation (tpi gene detection) of isolates as performed in previous studies (RodriguezPalacios et al., 2009).

The isolates confirmed as $C$. difficile were cultured on sheep blood agar under anaerobic conditions at $37{ }^{\circ} \mathrm{C}$ for two days. After culture, a thick bacterial cell suspension was prepared in $1 \mathrm{~mL}$ universal stool buffer (RIDASCREEN, R-Biopharm AG, Darmstadt, Germany) and centrifuged at $3000 \times \mathrm{g}$ for $10 \mathrm{~min}$. The supernatants were tested for the presence of $C$. difficile toxins A or B by enzyme linked immunosorbent assay (ELISA) detection kit (RIDASCREEN, R-Bio- 
pharm AG, Darmstadt, Germany) as per manufacturer's instructions. Positive and negative controls were included in each batch.

The results of the prevalence testing are summarised in Table 1. In total, six of $570(1.2 \%)$ samples were $C$. difficile positive. C. difficile strains were isolated from a sample of hamburger $(1.0 \%)$ and from five samples of minced beef meat $(3.3 \%)$, but not from any of the samples of chicken nugget, sausage and canned meat. Among the six $C$. difficile isolates five $(83.3 \%)$ were found to be toxigenic for toxin A and/or B. Recently published studies report the isolation of $C$. difficile from meat and meat products in relatively high percentages, ranging from 2.4 to over $42 \%$ of samples collected at retail (Simango \& Mwakurudza, 2008; RodriguezPalacios et al., 2009; Von Abercron et al., 2009; Weese et al., 2010). In a recent study in Iran, toxigenic $C$. difficile were detected from $2 / 7$ (28.5\%) hamburger processing plants, in $3 / 54(5.6 \%)$ of beef meat samples, $2 / 56(3.5 \%)$ of swabs taken from the environment and 4/56 (7.1\%) of hamburger samples after both molding and freezing (Esfandiar et al., 2014). In a study reported from Iran by Rahimi et al. (2014a), 13 of 660 meat samples $(2 \%)$ including buffalo, beef, cow, sheep, and goat meat were contaminated with $C$. dif- ficile. The highest prevalence of $C$. difficile was found in buffalo meat $(9 \%)$. In another study conducted in Isfahan, Chaharmahal va Bakhtiari, and Khuzestan province of Iran, $C$. difficile was identified in $1.43 \%$ of 135 bulk milk samples (Rahimi et al., 2014b).

The first specific investigation of $C$. difficile contamination of retail meat intended for human consumption was a study from Canada in 2007 (RodriguezPalacios et al., 2007). By enrichment culture, $C$. difficile was isolated from 12 of $60(20 \%)$ samples $(21 \%$ ground beef and $14 \%$ ground veal). The most common strain, accounting for $67 \%$ of isolates, was a toxigenic strain that possessed genes encoding TcdA, TcdB and CDT, belonging to toxinotype III. A similar study from the USA, using convenience sampling from stores in the Tuscon, Arizona area, reported isolation of $C$. difficile from 37 of $88(42 \%)$ samples, including ground beef $(13 / 26,50 \%)$, summer sausage $(1 / 7$, $14 \%)$, ground pork $(3 / 7,43 \%)$, braunschweiger $(10 / 16,63 \%)$, chorizo (3/10, $30 \%)$, pork sausage $(3 / 13,23 \%)$ and ground turkey $(4 / 9,44 \%)$ (Songer et al., 2009). In another study in Pittsburgh, Pennsylvania, USA, the isolation rates of $C$. difficile in ground meat and sausage samples were $2 \%$ (2 of 102) (Curry et al., 2012). In contrast, $C$. difficile was not

Table 1. Prevalence of Clostridium difficile detected in meat product samples in Iran

\begin{tabular}{lccc}
\hline Meat products & $\begin{array}{c}\text { Number of } \\
\text { samples }\end{array}$ & $\begin{array}{c}\text { Number of } C \text {. difficile- } \\
\text { positive samples }\end{array}$ & $\begin{array}{c}\text { Number of isolates positive } \\
\text { for toxins A and/or B }\end{array}$ \\
\hline Hamburger & 100 & $1(1.0 \%)^{*}$ & $1(1.0 \%)$ \\
Minced meat & 150 & $5(3.3 \%)$ & $4(2.7 \%)$ \\
Chicken nugget & 150 & 0 & 0 \\
Sausage & 100 & 0 & 0 \\
Canned meat & 70 & 0 & 0 \\
\hline Total & 570 & $6(1.2 \%)$ & $5(0.9 \%)$ \\
\hline
\end{tabular}

${ }^{*}$ Results expressed as number of $C$. difficile-positive samples/number of samples analysed (\%). 
isolated from any of 51 beef, 27 pork and six chicken samples in Austria (Indra et al., 2009). Also, Jöbstl et al. (2010) reported a low prevalence of $3 \%$ for $C$. difficile in retail ground meat samples; positive samples could only be found among mixed beef and pork samples, but not among ground beef (Jöbstl et al., 2010).

The source of $C$. difficile in meat is not clear. Carcasses may become contaminated with faecal material or from the environment during the slaughtering process. Contamination at retail level may also occur from the environment or through transmission by food handlers. The excellent survival of $C$. difficile spores in the environment increases the possibilities for contamination of animals and foods.

Quantification of $C$. difficile contamination in retail meat showed that generally low numbers, ranging from 60 to 240 spores/g, can be found (Weese et al., 2010). The meaning of this is not clear, as the infectious dose for $C$. difficile is not known. This and other published studies show that there is a potential for transmission of $C$. difficile to humans via the food chain. Also, this study shows the importance of minced beef meat as potential source of $C$. difficile infection in people.

\section{REFERENCES}

Bauer, M. P., D. Veenendaal, L. Verhoef, P. Bloembergen, J. T. van Dissel \& E. J. Kuijper, 2009. Clinical and microbiological characteristics of community-onset Clostridium difficile infection in The Netherlands. Clinical Microbiology and Infection, 15, 1087-1092.

Chernak, E., C. C. Johnson, A. Weltman, L. C. Mcdonald, L. Wiggs, G. Killgore, A. Thompson, M. Lemaile-Williams, E. Tan \& F. M. Lewis, 2005. Severe Clostridium difficile-associated disease in populations previously at low risk - four states. Morbidity and Mortality Weekly Report, 54, 1201-1205.

Curry, S. R., J. W. Marsh, J. L. Schlackman \& L. H. Harrison, 2012. Prevalence of Clostridium difficile in uncooked ground meat products from Pittsburgh, Pennsylvania. Applied and Environmental Microbio$\log y$, 78, 4183-4186.

de Boer, E., A. Zwartkruis-Nahuis, A. E. Heuvelink, C. Harmanus \& E. J. Kuijper, 2011. Prevalence of Clostridium difficile in retailed meat in The Netherlands. International Journal of Food Microbiology, 144, 561-564.

Esfandiari, Z., J. S. Weese, H. Ezzatpanah, M. Jalali \& M. Chamani, 2014. Occurrence of Clostridium difficile in seasoned hamburgers and seven processing plants in Iran. BMC Microbiology, 14, 283.

Goorhuis, A., S. B. Debast, L. A. van Leengoed, C. Harmanus, D. W. Notermans, A. A. Bergwerff \& E. J. Kuijper, 2008. Clostridium difficile PCR ribotype 078: An emerging strain in humans and in pigs? Journal of Clinical Microbiology, 46, 1157-1158.

Goorhuis, A., T. Van der Kooi, N. Vaessen, F. W. Dekker, R. Van den Berg, C. Harmanus, S. Van den Hof, D. W. Notermans \& E. J. Kujjper, 2007. Spread and epidemiology of Clostridium difficile polymerase chain reaction ribotype 027/ toxinotype III in The Netherlands. Clinical Infectious Diseases, 45, 695-703.

Harvey, R. B., Norman, K. N., Andrews, K., Hume, M. E., Scanlan, C. M., Callaway, T. R., R. C. Anderson \& D. J. Nisbet, 2011. Clostridium difficile in poultry and poultry meat. Foodborne Pathogen and Disease, 8, 1321-1323.

Hubert, B., V. Loo, A. Bourgault, L. Poirier, A. Dascal, M. Lorange, M. Dionne \& E. Fortin, 2007. A portrait of the geographic dissemination of the Clostridium difficile North American pulsed-field type 1 strain and the epidemiology of $C$. difficileassociated disease in Quebec. Clinical Infectious Diseases, 44, 238-244. 
Indra, A., Schmid, D., Huhulescu, S., Hell, M., Gattringer, R., Hasenberger, P., A. Findeler, G. Wewalka \& F. Allerberger, 2008. Characterization of clinical Clostridium difficile isolates by PCR ribotyping and detection of toxin genes in Austria, 2006-2007. Journal of Medical Microbiology, 57, 702-708.

Jalali, M., F. Khorvash, K. Warriner \& J. S. Weese, 2012. Clostridium difficile infection in an Iranian hospital. $B M C R e-$ search Notes, 5, 159.

Jöbstl, M., S. Heuberger, A. Indra, R. Nepf, J. Köfer \& M. Wagner, 2010. Clostridium difficile in raw products of animal origin. International Journal of Food Microbiology, 138, 172-175.

MacCannel, D., T. Louie, D. Gregson, M. Laverdiere, A. C. Labbe, F. Laing \& S. Henwick, 2006. Molecular analysis of Clostridium difficile PCR ribotype 027 isolates from Eastern and Western Canada. Journal of Clinical Microbiology, 44, 2147-2152.

Pituch, H., J. S. Brazier, P. Obuch-Woszczatynski, D. Wultanska, F. Meisel-Mikolajczyk \& M. Luczak, 2006. Prevalence and association of PCR ribotypes of Clostridium difficile isolated from symptomatic patients from Warsaw with macrolide-lincosamide-streptogramin B (MLSB) type resistance. Journal of Medical Microbiology, 55, 207-213.

Rahimi, E., M. Jalali \& J. S. Weese, 2014a. Prevalence of Clostridium difficile in raw beef, cow, sheep, goat, camel and buffalo meat in Iran. BMC Public Health, 14, 119.

Rahimi, E., H. Momtaz \& M. Hemati, 2014b. Occurrence of Clostridium difficile in raw bovine, ovine, caprine, camel and buffalo milk in Iran. Kafkas Universitesi Veteriner Fakultesi Dergisi, 20, 371-374.

Rodriguez-Palacios, A., H. R. Staempfli, T. Duffield \& J. S. Weese, 2007. Clostridium difficile in retail ground meat, $\mathrm{Ca}-$ nada. Emerging Infectious Diseases, 13, 485-487.

Rodriguez-Palacios, A., R. J. Reid-Smith, H. R. Staempfli, D. Daignault, N. Janecko, B. P. Avery, H. Martin, A. D. Thomp- son, L. C. Mcdonald, B. Limbago \& J. S. Weese, 2009. Possibility of seasonality of Clostridium difficile in retail meat, Canada. Emerging Infectious Diseases, 15, 802-805.

Rupnik, M., M. H. Wilcox \& D. N. Gerding, 2009. Clostridium difficile infection: New developments in epidemiology and pathogenesis. Nature Reviews Microbio$\log y$, 7, 526-536.

Simango, C. \& S. Mwakurudza, 2008. Clostridium difficile in broiler chickens sold at market places in Zimbabwe and their antimicrobial susceptibility. International Journal of Food Microbiology, 124, 268-270.

Songer, J. G., H. T. Trinh, G. E. Killgore, A. D. Thompson, L. C. McDonald \& B. M. Limbago, 2009. Clostridium difficile in retail meat products, USA 2007. Emerging Infectious Diseases, 15, 819-821.

Von Abercron, S. M. M., F. Karlsson, G. T. Wigh, M.Wierup \& K. Krovacek, 2009. Low occurrence of Clostridium difficile in retail ground meat in Sweden. Journal of Food Protection, 72, 1732-1734.

Weese, J. S., 2010. Clostridium difficile in food - innocent bystander or serious threat? Clinical Microbiology and Infection, 16, 3-10.

Wilcox, M. H., L. Mooney, R. Bendall, C. D. Settle \& W. N. Fawley, 2008. A case-control study of community-associated Clostridium difficile infection. Journal of Antimicrobial Chemotherapy, 62, 388-396.

Paper received 20.07.2014; accepted for publication 21.11.2014

\section{Correspondence:}

Ebrahim Rahimi

Department of Food Hygiene,

Faculty of Agriculture, Shahrekord Branch, Islamic Azad University, Shahrekord, Iran Tel: +98 381 3361060, Fax: +98 3116259809 e-mail: ebrahimrahimi55@yahoo.com 